\title{
Relationship between total cholesterol level and tuberculosis risk in a nationwide longitudinal cohort
}

Yong Suk Jo, 11, Kyungdo Han ${ }^{2,11}$, Dahye Kim ${ }^{3}$, Jung Eun Yoo ${ }^{4}$, Yuji Kim ${ }^{5}$, Bumhee Yang ${ }^{6}$, Hayoung Choi ${ }^{7}$, Jang Won Sohn ${ }^{8}$, Dong Wook Shin ${ }^{9,10,11 \bowtie}$ \& Hyun Lee Le,11凶 $^{8}$

The association between the total cholesterol level and tuberculosis (TB) risk has been controversial. Our study aimed to evaluate whether total cholesterol level can predict the risk of TB. Data from $5,000,566$ subjects who participated in a health screening exam in 2009 were investigated using the Korean National Health Insurance Service database (2009-2018). Cox hazard regression analyses were used to evaluate TB risk according to the quartile of total cholesterol levels. During an average of 8.2 years of follow-up, 32,078 cases of TB occurred. There was a significant inverse association between the total cholesterol level and TB risk. Compared with subjects in the highest quartile, those in the lowest quartile had a 1.35 -fold increased TB risk ( $95 \%$ confidence interval $=1.31-$ 1.39). The association between total cholesterol level and TB risk was more apparent in young subjects (age $<65$ years), those without diabetes mellitus (DM), and those without obesity ( $p$ for interaction $<0.001$ for age group, DM, and body mass index). Although there was a significant inverse association between total cholesterol level and TB risk in subjects who did not use a statin, no significant association was observed between the total cholesterol level and TB risk in subjects who used a statin. A low total cholesterol level was significantly associated with an increased risk of TB, even after adjusting for confounders, especially in patients younger than 65 years, those without DM or obesity, and those who did not use a statin.

\author{
Abbreviations \\ BMI Body mass index \\ COPD Chronic obstructive pulmonary disease \\ CKD Chronic kidney disease \\ DM Diabetes mellitus \\ HDL High-density lipoprotein \\ ICD-10 International Classification of Diseases 10th Revision \\ HR Hazard ratio
}

\footnotetext{
${ }^{1}$ Division of Pulmonary, Allergy, and Critical Care Medicine, Department of Internal Medicine, Hallym University Kangdong Sacred Heart Hospital, Seoul, Korea. ${ }^{2}$ Department of Statistics and Actuarial Science, Soongsil University, Seoul, Korea. ${ }^{3}$ Department of Biostatistics, The Catholic University of Korea, Seoul, Republic of Korea. ${ }^{4}$ Department of Family Medicine, Healthcare System Gangnam Center, Seoul National University Hospital, Seoul, Republic of Korea. ${ }^{5}$ Division of Endocrinology and Metabolism, Department of Internal Medicine, Jeonbuk National University Hospital, Jeonju, Korea. ${ }^{6}$ Division of Pulmonary and Critical Care Medicine, Department of Internal Medicine, Chungbuk National University Hospital, Chungbuk National University College of Medicine, Cheongju, Korea. ${ }^{7}$ Division of Pulmonary, Allergy, and Critical Care Medicine, Department of Internal Medicine, Hallym University Kangnam Sacred Heart Hospital, Hallym University College of Medicine, Seoul, Korea. ${ }^{8}$ Division of Pulmonary Medicine and Allergy, Department of Internal Medicine, Hanyang University College of Medicine, 222-1, Wangsimni-ro, Seongdong-gu, Seoul 04763, Korea. ${ }^{9}$ Department of Family Medicine/Supportive Care Center, Samsung Medical Center, Sungkyunkwan University School of Medicine, 81 Irwon-Ro, Gangnam-gu, Seoul 06351, Korea. ${ }^{10}$ Department of Clinical Research Design and Evaluation, SAIHST, Sungkyunkwan University, Seoul, Korea. ${ }^{11}$ These authors contributed equally: Yong Suk Jo, Kyungdo Han, Dong Wook Shin and Hyun Lee. ${ }^{\bowtie}$ email: dwshin.md@gmail.com; namuhanayeyo@hanyang.ac.kr
} 
LDL Low-density lipoprotein

NHIS National Health Insurance Service

OECD Organization for Economic Cooperation and Development

Q1 The lowest quartile

Q4 The highest quartile

TB Tuberculosis

Tuberculosis (TB) is one of the oldest diseases and remains a leading cause of death from an infectious disease ${ }^{1}$. In South Korea, the incidence and mortality rates for TB were 66 and 4.7 per 100,000 people, respectively, in 2018, which is five to six-fold higher than the average in the Organization for Economic Cooperation and Development (OECD) countries ${ }^{2}$. Although the occurrence of TB has been decreasing thanks to a nationwide, multifaceted effort, South Korea had the highest incidence and mortality rates for TB among OECD countries. Despite the historical prevalence of TB in Korea, socioeconomic development has made Korea a high-income country, which has substantially reduced the traditional risk factors for TB-poverty, undernutrition, and low body mass index $(\mathrm{BMI})^{3-5}$. On the other hand, metabolic conditions (e.g., obesity, dyslipidemia, and diabetes mellitus $[\mathrm{DM}])^{5-11}$ which could alter the TB risk have increased in South Korea. Many developing countries with an intermediate-high TB burden face situations similar to that of South Korea; therefore, studies evaluating the relationship between metabolic diseases and TB risk will be important to those countries.

Cholesterol is a key component of the cell membrane and plays a crucial role in several metabolic pathways ${ }^{12}$. It has been suggested that altered lipid metabolism can affect susceptibility to TB. However, conflicting data about the relationship between the total cholesterol level and TB risk have been published ${ }^{6-8}$. Some researchers suggested that a low cholesterol level is associated with an increased risk of TB by showing that cholesterol levels decreased in patients with $\mathrm{TB}^{6}$. Supporting that view, studies showed that low cholesterol levels correlate with disease severity ${ }^{13,14}$. In contrast, other researchers suggested that low cholesterol levels in patients with TB are merely a consequence of the disease because TB treatment significantly increases low cholesterol levels ${ }^{7,8}$. Therefore, whether a low total cholesterol level is a contributing factor in TB or a consequence of the disease has been unclear. The relationship between a high cholesterol level and TB risk is also suggested. A positive association between a cholesterol-rich diet and TB risk in a cohort study of Singapore ${ }^{15}$ and study results indicating that latent TB treatment decreases the total cholesterol level ${ }^{16}$ suggest that a high cholesterol level might reflect a high TB risk status. In line with those results, hypercholesterolemia was shown to impair immunity to TB in animal models ${ }^{9}$.

Furthermore, cholesterol levels and TB risk are both affected by factors such as $\mathrm{BMI}^{5}, \mathrm{DM}$ status ${ }^{10}$, and statin use ${ }^{17}$, which makes understanding the association between them difficult. Therefore, studies evaluating the association between cholesterol and TB risk need to consider those factors. In this study, we aimed to identify the association between cholesterol level and the risk of TB using a nationwide cohort from South Korea while also considering the effects of BMI, DM, and the use of a statin on the association.

\section{Results}

Baseline characteristics. Table 1 summarizes the comparison of clinical features between the subjects who developed TB and those who did not. Subjects who developed TB were older (mean 56.1 years vs. 47.1 years, $p<0.001)$ and more likely to be male $(58.9 \%$ vs. $54.6 \%, p<0.001)$ than those who did not. Compared with subjects who did not develop TB, those who developed TB had a lower BMI (mean $22.6 \mathrm{~kg} / \mathrm{m}^{2} \mathrm{vs}$. $\left.23.7 \mathrm{~kg} / \mathrm{m}^{2}, p<0.001\right)$ and lower incomes $(22.0 \%$ vs. $78.5 \%, p=0.026)$. Subjects who developed TB had more comorbid conditions, including DM, hypertension, dyslipidemia, heart disease, stroke, chronic kidney disease (CKD), and chronic airway diseases (asthma or chronic obstructive pulmonary disease [COPD]) $(p<0.001$ for all comorbidities) than those who did not develop TB. In contrast, subjects who developed TB were less likely to do regular physical activity $(17.3 \%$ vs. $18.2 \%, p<0.001)$ than those who did not. The mean or median levels of total cholesterol $(191.0 \pm 37.9$ vs. $195.1 \pm 36.8 \mathrm{mg} / \mathrm{dL})$, low-density lipoprotein (LDL) cholesterol $(109.9 \pm 34.8$ vs. $113.2 \pm 33.9 \mathrm{mg} / \mathrm{dL})$, and triglycerides $(110.7[110.1-111.4]$ vs. $112.2[112.2-112.3] \mathrm{mg} / \mathrm{dL})$ were lower in subjects who developed TB than in those who did not $(p<0.001$ for all variables). However, statin use was more common in subjects who developed TB than in those who did not $(9.8 \%$ vs. $7.6 \%, p<0.001)$.

Total cholesterol level and TB risk. During an average of 8.2 years of follow-up, 32,078 cases of TB occurred after the enforced 1-year lag time. As shown in Table 2, we found an inverse relationship between the total cholesterol level and the risk of TB. Compared with subjects in the highest quartile, those in the lowest quartile for total cholesterol had the highest risk of TB overall, even after adjusting for multiple clinical variables, including statin use (model 2) (adjusted hazard ratio $[\mathrm{HR}]=1.35,95 \%$ confidence interval $=1.31-1.39$ ). In addition, there was an inverse relationship between the time to TB development and total cholesterol level (the time to TB development was 3.9 \pm 2.4 years in Q1 [the lowest quartile] group, $4.0 \pm 2.5$ years in Q2 group, $4.1 \pm 2.4$ years in Q3 group, and 4.2 \pm 2.4 years in Q5 [the highest quartile] group, respectively). The associations between the individual lipid levels and the risk of TB are summarized in Supplemental Table S1.

Total cholesterol level and TB risk in subgroups. Table 2 shows the association between the total cholesterol level and TB incidence in subgroups. Across all subgroups, there was an inverse relationship between the total cholesterol level and TB risk. There were significant interactions between total cholesterol level and age, BMI, and DM. The association between total cholesterol level and age in the development of TB was more evident in the younger group ( $<65$ years) than in the older group ( $\geq 65$ years) ( $p$ for interaction $<0.001$ in model 2 ). The interaction between total cholesterol level and BMI in the development of TB showed a more substan- 


\begin{tabular}{|c|c|c|c|c|}
\hline & Total $(\mathrm{N}=5,000,566)$ & Patients who did not develop TB $(n=4,968,488)$ & Patients who developed TB $(n=32,078)$ & $p$ value \\
\hline Age, years & $47.2 \pm 14.1$ & $47.1 \pm 14.1$ & $56.1 \pm 15.8$ & $<0.001$ \\
\hline Sex, male & $2,732,571(54.7)$ & $2,713,664(54.6)$ & $18,907(58.9)$ & $<0.001$ \\
\hline Body mass index, $\mathrm{kg} / \mathrm{m}^{2}$ & $23.7 \pm 3.2$ & $23.7 \pm 3.2$ & $22.6 \pm 3.1$ & $<0.001$ \\
\hline \multicolumn{5}{|l|}{ Smoking status } \\
\hline Never & $2,983,062(59.7)$ & $2,964,482(59.7)$ & $18,580(57.9)$ & $<0.001$ \\
\hline Ex & $712,535(14.2)$ & $707,910(14.3)$ & $4625(14.4)$ & \\
\hline Current & $1,304,969(26.1)$ & $129,6097(26.1)$ & $8872(27.7)$ & \\
\hline Low income & $1,075,880(21.5)$ & $78.5(21.5)$ & $78.0(22.0)$ & 0.026 \\
\hline \multicolumn{5}{|l|}{ Alcohol consumption } \\
\hline No & $2,585,695(51.7)$ & $2,567,446(51.7)$ & $18,249(56.9)$ & $<0.001$ \\
\hline Mild & $2,020,311(40.4)$ & $2,009,501(40.4)$ & $10,810(33.7)$ & \\
\hline Heavy & $394,560(7.9)$ & $391,542(7.9)$ & $3018(9.4)$ & \\
\hline \multicolumn{5}{|l|}{ Comorbid conditions } \\
\hline Diabetes mellitus & $436,055(8.7)$ & $430,767(8.7)$ & $5049(15.7)$ & $<0.001$ \\
\hline Hypertension & $1,350,494(27.0)$ & $1,338,510(26.9)$ & $11,904(37.1)$ & $<0.001$ \\
\hline Dyslipidemia & $909,576(18.2)$ & $903,271(18.2)$ & $6152(19.2)$ & $<0.001$ \\
\hline Heart disease & $99,770(3.2)$ & $156,010(3.1)$ & $1703(5.3)$ & $<0.001$ \\
\hline Stroke & $51,644(1.6)$ & $80,986(1.6)$ & $741(2.3)$ & $<0.001$ \\
\hline $\begin{array}{l}\text { Chronic kidney disease, GFR }<30 \mathrm{~mL} / \mathrm{min} / 1.73 \\
\mathrm{~m}^{2}\end{array}$ & $72,882(1.5)$ & $72,363(1.5)$ & $519(1.6)$ & $<0.001$ \\
\hline Asthma or COPD & $416,492(8.3)$ & $411,887(8.3)$ & 4689 (14.6) & $<0.001$ \\
\hline Regular physical activity & $907,094(18.1)$ & $901,780(18.2)$ & $5533(17.3)$ & $<0.001$ \\
\hline \multicolumn{5}{|l|}{ Lipid profile } \\
\hline Total cholesterol level, mg/dL & $195.1 \pm 36.8$ & $195.1 \pm 36.8$ & $191.0 \pm 37.9$ & $<0.001$ \\
\hline LDL cholesterol, mg/dL & $113.2 \pm 33.9$ & $113.2 \pm 33.9$ & $109.9 \pm 34.8$ & $<0.001$ \\
\hline Triglycerides, mg/dL & $112.2(112.2-112.3)$ & $112.2(112.2-112.3)$ & $110.7(110.1-111.4)$ & $<0.001$ \\
\hline HDL cholesterol, mg/dL & $55.2 \pm 17.3$ & $55.2 \pm 17.2$ & $55.4 \pm 21.5$ & $<0.001$ \\
\hline Statin use & $381,229(7.6)$ & $378,101(7.6)$ & $3153(9.8)$ & $<0.001$ \\
\hline
\end{tabular}

Table 1. Demographic data of subjects. Data are presented as mean \pm standard deviation or median (interquartile range) for continuous variables and number (\%) for categorical variables. TB tuberculosis, GFR glomerular filtration rate, $H D L$ high-density lipoprotein, $L D L$ low-density lipoprotein.

tial association in non-obese patients $\left(B M I<25 \mathrm{~kg} / \mathrm{m}^{2}\right)$ than in obese patients $\left(\mathrm{BMI} \geq 25 \mathrm{~kg} / \mathrm{m}^{2}\right)$ ( $p$ for interaction $<0.001$ in model 2). Also, the association between total cholesterol level and TB risk was more evident in patients without DM than in those with DM ( $p$ for interaction $<0.001$ in model 2 ). We found no significant interactions between the total cholesterol level and the other covariates (sex, alcohol use, physical activity, smoking, and CKD) in the development of TB (data not shown).

The effect of statin use on the association between total cholesterol level and TB risk. The relationship between the total cholesterol level and the development of TB according to statin use is presented in Fig. 1. In the crude model, there was an inverse relationship between the total cholesterol level and TB risk regardless of statin use. However, after adjustment for the covariables, the association between the total cholesterol level and TB risk differed significantly by statin use ( $p$ for interaction $<0.001$ ). Among patients who did not receive a statin, there was an inverse association between total cholesterol level and TB risk, but that association lost its significance in patients who used a statin.

\section{Discussion}

In this large population-based longitudinal study, we identified a clear relationship between a low total cholesterol level and high TB risk. The major strength of our study is that we used the largest-ever cohort with adequate lipid profile information. The inverse relationship between the total cholesterol level and TB risk was shown consistently in the subgroups, even after adjusting for potential confounding factors. In addition, we found that the effect of low total cholesterol on the development of TB was more robust in the following subgroups: younger age group, non-obese group, and non-DM group. When analyzed by statin use, whereas a significant inverse association existed between the total cholesterol level and TB risk in subjects not receiving statins, no significant association was observed between the total cholesterol level and TB risk in subjects receiving statins.

Some previous cross-sectional studies have suggested an inverse association between the total cholesterol level and $\mathrm{TB}^{6-8}$. According to those studies, patients with $\mathrm{TB}$ had significantly lower cholesterol levels than those without $\mathrm{TB}^{6-8}$, and anti-TB treatment improved their cholesterol levels ${ }^{7,8}$. However, those studies were limited by their cross-sectional designs and relatively small study populations. Furthermore, those studies did 


\begin{tabular}{|c|c|c|c|c|c|c|c|c|}
\hline & \multirow[b]{2}{*}{$\begin{array}{l}\text { Quartile of } \\
\text { TC level }\end{array}$} & \multirow[b]{2}{*}{$\begin{array}{l}\text { Number at } \\
\text { risk }\end{array}$} & \multirow[b]{2}{*}{ Cases } & \multirow[b]{2}{*}{$\begin{array}{l}\text { Duration } \\
\text { (PY) }\end{array}$} & \multirow[b]{2}{*}{$\begin{array}{l}\text { IR }(10,000 \\
\text { PY) }\end{array}$} & \multicolumn{3}{|c|}{ HR $(95 \%$ CI $)$} \\
\hline & & & & & & $\begin{array}{l}\text { Crude } \\
\text { model }\end{array}$ & Model 1 & Model 2 \\
\hline \multirow{4}{*}{ Overall } & Q1 & $1,254,432$ & 9546 & $10,225,250$ & 9.3 & $\begin{array}{l}1.35 \\
(1.31-1.39) \\
\end{array}$ & $\begin{array}{l}1.34(1.29- \\
1.38)\end{array}$ & $\begin{array}{l}1.35 \\
(1.31-1.39) \\
\end{array}$ \\
\hline & Q2 & $1,255,891$ & 8045 & $10,301,441$ & 7.8 & $\begin{array}{l}1.13 \\
(1.09-1.16)\end{array}$ & $\begin{array}{l}1.15(1.11- \\
1.19)\end{array}$ & $\begin{array}{l}1.15 \\
(1.11-1.19)\end{array}$ \\
\hline & Q3 & $1,238,977$ & 7362 & $10,173,668$ & 7.2 & $\begin{array}{l}1.04 \\
(1.01-1.08)\end{array}$ & $\begin{array}{l}1.06(1.02- \\
1.09)\end{array}$ & $\begin{array}{l}1.05 \\
(1.02-1.09)\end{array}$ \\
\hline & Q4 & $1,251,266$ & 7125 & $10,269,940$ & 6.9 & Ref & Ref & Ref \\
\hline \multicolumn{9}{|l|}{ Age group } \\
\hline \multirow{4}{*}{ Age $<65$ years } & Q1 & $1,099,255$ & 6185 & $9,071,739$ & 6.8 & $\begin{array}{l}1.40 \\
(1.34-1.45)\end{array}$ & $\begin{array}{l}1.33(1.27- \\
1.38)\end{array}$ & $\begin{array}{l}1.34 \\
(1.28-1.38)\end{array}$ \\
\hline & Q2 & $1,104,052$ & 5223 & $9,133,888$ & 5.7 & $\begin{array}{l}1.17 \\
(1.12-1.22)\end{array}$ & $\begin{array}{l}1.15(1.10- \\
1.19)\end{array}$ & $\begin{array}{l}1.15 \\
(1.10-1.19)\end{array}$ \\
\hline & Q3 & $1,076,909$ & 4697 & $8,915,017$ & 5.3 & $\begin{array}{l}1.08 \\
(1.04,1.12)\end{array}$ & $\begin{array}{l}1.07(1.02- \\
1.11)\end{array}$ & $\begin{array}{l}1.07 \\
(1.02-1.11)\end{array}$ \\
\hline & Q4 & $1,064,651$ & 4304 & $8,809,225$ & 4.9 & Ref & Ref & Ref \\
\hline \multirow{5}{*}{ Age $\geq 65$ years } & Q1 & 155,177 & 3361 & $1,153,511$ & 29.1 & $\begin{array}{l}1.51 \\
(1.44-1.59) \\
\end{array}$ & $\begin{array}{l}1.24(1.18- \\
1.30)\end{array}$ & $\begin{array}{l}1.27 \\
(1.21-1.34) \\
\end{array}$ \\
\hline & Q2 & 151,839 & 2822 & $1,167,553$ & 24.2 & $\begin{array}{l}1.25 \\
(1.19-1.32) \\
\end{array}$ & $1.1(1.044,1.16)$ & $\begin{array}{l}1.11 \\
(1.05-1.17)\end{array}$ \\
\hline & Q3 & 162,068 & 2665 & $1,258,651$ & 21.2 & $\begin{array}{l}1.10 \\
(1.04-1.16)\end{array}$ & $\begin{array}{l}1.02(0.97- \\
1.07)\end{array}$ & $\begin{array}{l}1.02 \\
(0.96-1.07)\end{array}$ \\
\hline & Q4 & 186,615 & 2821 & $1,460,715$ & 19.3 & Ref & Ref & Ref \\
\hline & \multicolumn{5}{|c|}{$p$ for interaction } & 0.048 & $<0.001$ & $<0.001$ \\
\hline \multicolumn{9}{|l|}{ BMI group } \\
\hline \multirow{4}{*}{$\mathrm{BMI}<18.5 \mathrm{~kg} / \mathrm{m}^{2}$} & Q1 & 79,333 & 1116 & 634,825 & 17.6 & $\begin{array}{l}0.92 \\
(0.81-1.05)\end{array}$ & $1.32(1.16,1.50)$ & $\begin{array}{l}1.32 \\
(1.16-1.50)\end{array}$ \\
\hline & Q2 & 51,621 & 656 & 414,654 & 15.8 & $\begin{array}{l}0.83 \\
(0.72-0.95) \\
\end{array}$ & $\begin{array}{l}1.11(0.96- \\
1.27)\end{array}$ & $\begin{array}{l}1.11 \\
(0.97-1.27)\end{array}$ \\
\hline & Q3 & 33,575 & 448 & 268,167 & 16.7 & $\begin{array}{l}0.87 \\
(0.76-1.01)\end{array}$ & $\begin{array}{l}1.03(0.89- \\
1.19)\end{array}$ & $\begin{array}{l}1.02 \\
(0.89-1.19)\end{array}$ \\
\hline & Q4 & 19,846 & 300 & 156,634 & 19.2 & Ref & Ref & Ref \\
\hline \multirow{4}{*}{$\begin{array}{l}18.5 \leq \mathrm{BMI}<23.0 \mathrm{~kg} / \\
\mathrm{m}^{2}\end{array}$} & Q1 & 598,823 & 52,57 & $4,880,828$ & 10.8 & $\begin{array}{l}1.09 \\
(1.04-1.14)\end{array}$ & $\begin{array}{l}1.35(1.29- \\
1.42)\end{array}$ & $\begin{array}{l}1.36 \\
(1.30-1.42)\end{array}$ \\
\hline & Q2 & 528,369 & 4160 & $4,327,498$ & 9.6 & $\begin{array}{l}0.97 \\
(0.93-1.02)\end{array}$ & $\begin{array}{l}1.16(1.10- \\
1.21)\end{array}$ & $\begin{array}{l}1.16 \\
(1.10-1.21)\end{array}$ \\
\hline & Q3 & 451,288 & 3550 & $3,695,960$ & 9.6 & $\begin{array}{l}0.97 \\
(0.92-1.02)\end{array}$ & $\begin{array}{l}1.07(1.02- \\
1.124)\end{array}$ & $\begin{array}{l}1.07 \\
(1.02-1.12)\end{array}$ \\
\hline & Q4 & 370,748 & 2999 & $3,028,541$ & 9.9 & Ref & Ref & Ref \\
\hline \multirow{4}{*}{$\begin{array}{l}23.0 \leq \mathrm{BMI}<25.0 \mathrm{~kg} / \\
\mathrm{m}^{2}\end{array}$} & Q1 & 273,821 & 1735 & $2,237,728$ & 7.8 & $\begin{array}{l}1.19 \\
(1.11-1.27)\end{array}$ & $\begin{array}{l}1.28(1.20- \\
1.37)\end{array}$ & $\begin{array}{l}1.31 \\
(1.23-1.41)\end{array}$ \\
\hline & Q2 & 304,809 & 1704 & $2,506,803$ & 6.8 & $\begin{array}{l}1.04 \\
(0.98-1.11)\end{array}$ & $\begin{array}{l}1.156 \\
(1.08-1.24)\end{array}$ & $\begin{array}{l}1.16 \\
(1.08-1.24)\end{array}$ \\
\hline & Q3 & 320,026 & 1663 & $2,634,080$ & 6.3 & $\begin{array}{l}0.97 \\
(0.91-1.03)\end{array}$ & $\begin{array}{l}1.037 \\
(0.97-1.11)\end{array}$ & $\begin{array}{l}1.03 \\
(0.97-1.11)\end{array}$ \\
\hline & Q4 & 333,575 & 1791 & $2,743,383$ & 6.5 & Ref & Ref & Ref \\
\hline \multirow{5}{*}{$\mathrm{BMI} \geq 25 \mathrm{~kg} / \mathrm{m}^{2}$} & Q1 & 302,455 & 1438 & $2,471,869$ & 5.8 & $\begin{array}{l}1.24 \\
(1.16-1.33)\end{array}$ & $\begin{array}{l}1.17(1.09- \\
1.25)\end{array}$ & $\begin{array}{l}1.18 \\
(1.11-1.27)\end{array}$ \\
\hline & Q2 & 371,092 & 1525 & $3,052,485$ & 5.0 & $\begin{array}{l}1.07 \\
(1.00-1.14)\end{array}$ & $\begin{array}{l}1.09(1.02- \\
1.17)\end{array}$ & $\begin{array}{l}1.10 \\
(1.03-1.17)\end{array}$ \\
\hline & Q3 & 434,088 & 1701 & $3,575,460$ & 4.8 & $\begin{array}{l}1.02 \\
(0.95-1.08)\end{array}$ & $\begin{array}{l}1.05(0.98- \\
1.12)\end{array}$ & $\begin{array}{l}1.05 \\
(0.98-1.12) \\
\end{array}$ \\
\hline & Q4 & 527,097 & 2035 & $4,341,382$ & 4.7 & Ref & Ref & Ref \\
\hline & \multicolumn{5}{|c|}{$p$ for interaction } & 0.001 & $<0.001$ & $<0.001$ \\
\hline \multicolumn{9}{|l|}{ Diabetes mellitus } \\
\hline \multirow{4}{*}{$\begin{array}{l}\text { Without diabetes } \\
\text { mellitus }\end{array}$} & Q1 & $1,140,206$ & 8035 & $9,336,142$ & 8.6 & $\begin{array}{l}1.36 \\
(1.31-1.40)\end{array}$ & $\begin{array}{l}1.40(1.34- \\
1.45)\end{array}$ & $\begin{array}{l}1.41 \\
(1.36-1.46)\end{array}$ \\
\hline & Q2 & $1,160,137$ & 6888 & $9,542,782$ & 7.2 & $\begin{array}{l}1.14 \\
(1.01-1.18)\end{array}$ & $\begin{array}{l}1.17(1.13- \\
1.22)\end{array}$ & $\begin{array}{l}1.17 \\
(1.13-1.22)\end{array}$ \\
\hline & Q3 & $1,138,970$ & 6231 & $9,376,755$ & 6.6 & $\begin{array}{l}1.05 \\
(1.01-1.09)\end{array}$ & $\begin{array}{l}1.06(1.03- \\
1.10)\end{array}$ & $\begin{array}{l}1.06 \\
(1.02-1.10)\end{array}$ \\
\hline & Q4 & $1,125,198$ & 5876 & $9,261,763$ & 6.3 & Ref & Ref & Ref \\
\hline
\end{tabular}




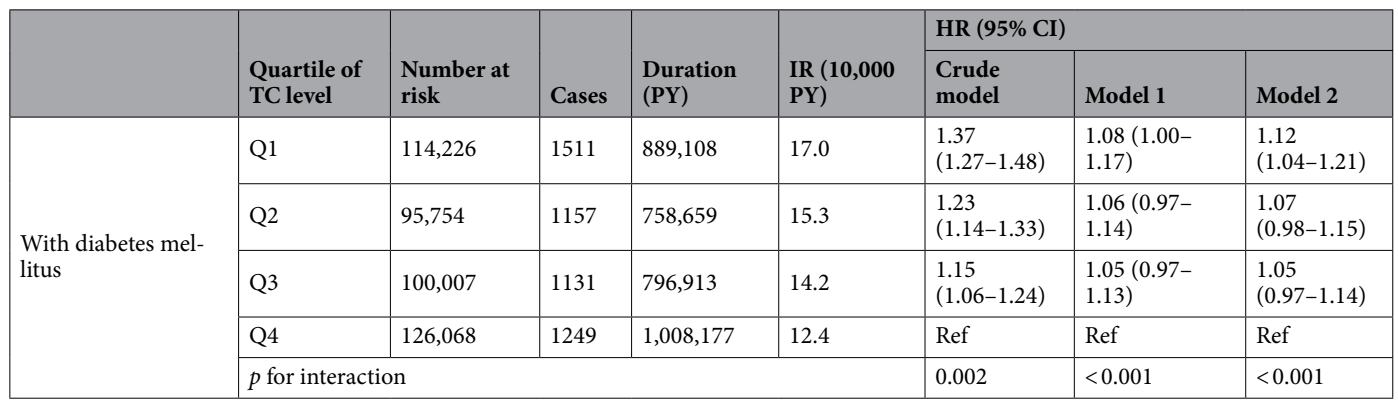

Table 2. TB risk by quartile of total cholesterol level. Data are presented as numbers and ratios (95\% CI), as appropriate. Model 1 is adjusted for age, sex, smoking status, drinking habits, physical activity, BMI, diabetes mellitus, asthma or COPD, and GFR. Model 2 is adjusted for age, sex, smoking status, drinking habits, physical activity, BMI, diabetes mellitus, asthma or COPD, GRF, and statin use. TC total cholesterol, PY person-years, $I R$ incidence rate, $H R$ hazard ratio, $C I$ confidence interval, $B M I$ body mass index, $Q 1$ the lowest quartile, $Q 4$ the highest quartile $B M I$ body mass index $C O P D$ chronic obstructive pulmonary disease, GFR glomerular filtration rate.

\begin{tabular}{|c|c|c|c|c|}
\hline Stain use & Total cholesterol & TB risk & HR $(95 \%$ CI $)$ & $\mathrm{P}$ for interaction \\
\hline \multirow{4}{*}{ No } & Q1 & \multirow{4}{*}{-} & $1.38(1.33-1.43)$ & \multirow{8}{*}{$<0.001$} \\
\hline & Q2 & & $1.15(1.12-1.19)$ & \\
\hline & Q3 & & $1.06(1.02-1.10)$ & \\
\hline & Q4 & & Ref & \\
\hline \multirow{4}{*}{ Yes } & Q1 & \multirow{4}{*}{$=$} & $1.10(0.99-1.21)$ & \\
\hline & Q2 & & $1.10(0.99-1.22)$ & \\
\hline & Q3 & & $1.02(0.91-1.14)$ & \\
\hline & $\mathrm{Q} 4$ & & Ref & \\
\hline
\end{tabular}

Figure 1. TB risk by quartile of total cholesterol level stratified by statin use. Age, sex, smoking status, drinking habits, physical activity, BMI, diabetes mellitus, asthma or COPD, and GFR were adjusted. TB tuberculosis, $H R$ hazard ratio, $C I$ confidence interval, Q1 the lowest quartile, Q4 the highest quartile, BMI body mass index, COPD chronic obstructive pulmonary disease, GFR glomerular filtration rate.

not consider confounding factors (e.g., low $\mathrm{BMI}^{5}$ and $\mathrm{DM}^{10,11}$ ) that can affect both lipid profiles and the development of TB. Therefore, the major strength of our study is that we clarified the inverse relationship between total cholesterol levels and TB risk in a longitudinal cohort study based on a large population, and we considered potential confounders.

The underlying mechanisms addressing the association between low cholesterol levels and TB risk are not well elucidated. Although the evaluation of those mechanisms is beyond our study scope, two explanations are plausible. First, a low cholesterol level could be a risk factor for TB. The innate and cell-mediated immune responses are key elements in the defense against $\mathrm{TB}^{18}$. The innate immune system recognizes $M$. tuberculosis through various pattern recognition receptors, which in turn activate phagocytosis, autophagy, and the inflammasome ${ }^{18}$. Activation of the cell-mediated immune system is known to promote the innate immune system (e.g., promotion of intraphagosomal killing of $M$. tuberculosis in macrophages $)^{18}$. The role of cholesterol in the immune system is yet to be comprehensively revealed, but data indicate that it might have an important role in both innate and cell-mediated immunity. Cells depleted of cholesterol have dysfunctional pattern recognition-mediated immune activation ${ }^{19,20}$. In particular, the phagocytosis of M. tuberculosis by murine macrophages was shown to be significantly decreased when cholesterol was depleted ${ }^{21}$. Also, a recent study showed that a reduced cholesterol level was associated with $\mathrm{T}$ cell proliferation and function ${ }^{22}$. The second possibility is that a low cholesterol level might merely be a sign of TB during the latent period, instead of being a risk factor for TB. Our study design could not distinguish the former from the latter, and all epidemiological studies evaluating causal inferences harbor this limitation. Therefore, a well-designed study is needed to further evaluate the causal inference and underlying mechanisms of the association between cholesterol levels and TB risk.

In this study, the association between the total cholesterol level and TB risk was more robust in the younger age group, non-obese group, and non-DM group. Although we found a significant interaction between cholesterol levels and age, the difference in $\mathrm{HR}$ was small ( $\mathrm{HR}=1.34$ in age $<65$ years and $\mathrm{HR}=1.27$ in age $\geq 65$ years) 
and might not be clinically relevant. It is well known that a high BMI is negatively associated with TB risk $^{5,23}$. In this study, BMI had a significant interaction with the total cholesterol level in terms of TB risk. Although the underlying mechanisms are not well known, it seems that the protective effect of a high BMI against the development of TB reduced the effect that a low cholesterol level had on TB risk. In subjects with DM, the effect of the total cholesterol level on TB risk was not as apparent as in those without DM. The increased TB risk caused by $\mathrm{DM}^{10}$ itself seems to have a more profound effect than a low cholesterol level in subjects with DM. It is also likely that DM-associated conditions that increase $\mathrm{TB}$ risk, such as $\mathrm{CKD}^{24}$, affect the impact of a low cholesterol level on TB risk.

Interestingly, the apparent association between a low cholesterol level and TB risk was not found in patients taking a statin. As an explanation for that phenomenon, we suggest that the increased TB risk caused by statininduced low cholesterol levels might have been offset by the immune system enhancement caused by statin use. For the disease progression of TB, the metabolism of macrophage cholesterol by M. tuberculosis is very important $t^{17,25}$. Because statins reduce macrophage cholesterol, as well as serum cholesterol ${ }^{26}$, the cholesterol metabolism by M. tuberculosis might be hindered by statins. Statins also have anti-inflammatory effects; recent studies showed that statins promote autophagy and phagosome activity in macrophages and enhance the secretion of proinflammatory cytokines by natural killer cells ${ }^{27,28}$.

The results of this study have several important clinical implications. First, low total cholesterol can be used as a predictor of TB in subjects already at high risk (e.g., subjects with a low BMI). Second, the results of our study should be interpreted cautiously. The inverse relationship between the total cholesterol level and TB risk in our study does not necessarily mean that a high-cholesterol diet can help to reduce TB risk in subjects with a high TB risk and low cholesterol level. Conflicting data have been published about the connection between a cholesterolrich diet and TB. A population-based study in Singapore showed that a high cholesterol diet could increase TB risk $^{15}$, and another study showed that a cholesterol-rich diet enhanced the sterilization of $M$. tuberculosis in the sputum of patients with pulmonary $\mathrm{TB}^{29}$. Accordingly, a well-designed study is needed to evaluate whether a high-cholesterol diet can prevent TB in high-risk subjects with low cholesterol. Third, our study results could be helpful to researchers investigating the mechanism of TB development by providing solid evidence about the inverse association between cholesterol levels and TB risk in humans.

Our study has several limitations. First, we used only one lipid profile per patient. Since not all participants were screened regularly as did in a prospective study, a study design including participants whose cholesterol levels were repeatedly measured was expected to cause several issues including selection bias and an increase in missing participants, which might decrease the statistical power of our study. However, as lipid profiles can vary over time, studies reflecting those variations are still needed. Second, we do not have detailed clinical information about TB, including the type and severity of the disease, because those details are not available in the Korean NHIS database. Third, our study was performed in a single country with an intermediate TB burden. Thus, our results might not be generalizable to the populations of countries with different TB burdens. However, our evaluation of a large number of subjects with lipid profile information is a strength of our study. Our study results could be beneficial to developing and developed countries with an intermediate TB burden.

In conclusion, we found an inverse association between total cholesterol levels and TB risk, and it was more robust in young subjects, those without DM, non-obese subjects, and those who did not use a statin. Future studies are needed to evaluate the underlying mechanisms by which cholesterol metabolism affects TB risk.

\section{Materials and methods}

Study population and design. We performed a population-based retrospective cohort study using information from the Korean National Health Insurance Service (NHIS) database ${ }^{30}$. In South Korea, a single-payer universal health system covers about $97 \%$ of all Korean citizens. Thus, the NHIS has claims data on every patient's use of medical facilities, including International Classification of Diseases 10th Revision (ICD-10) codes, procedures, and prescriptions from outpatient clinics, emergency departments, and hospitalizations. Furthermore, the NHIS has socio-demographic data on all subscribers, including age, sex, and income level.

The NHIS database also contains data from annual or biennial health screening exams offered free of charge by the Ministry of Health and Welfare to all beneficiaries aged 40 years and older and all employees regardless of age. Approximately $72 \%$ of all eligible persons undergo this screening ${ }^{31}$, the screening data contain the answers to a self-reported questionnaire on health behavior (i.e., smoking status, alcohol consumption, physical activity, and past medical history), anthropometric measurements (e.g., BMI and blood pressure), and laboratory tests (e.g., hemoglobin, creatinine, and lipid profiles).

This study initially included 5,292,827 subjects who were aged $\geq 20$ years and received a health screening exam between January 1, 2009, and December 31, 2009. We excluded individuals who had missing data for any variable $(n=273,848)$, those who were diagnosed with TB before the health screening $(n=1402)$, those diagnosed with TB within 1 year after the health screening $(n=3969)$, and those who died within 1 year after the health screening $(n=13,042)$. A history of TB was defined by the following criteria: (1) presence of ICD-10 code for A15-A19, U880, or U881 at least twice in the 6 months between January 1, 2002, and December 31, 2008 , or (2) findings of inactive TB, active TB, or suspected TB on chest radiography conducted as part of the health screening examination. In the end, we included 5,000,566 individuals in our analyses (Fig. 2). The cohort was followed from baseline to the date of incident TB or death or until the end of the study period (December $31,2018)$, whichever came first.

Definitions. Independent variable. For total cholesterol, LDL cholesterol, and triglycerides, the levels were classified and analysed by quartile (Q1 - the lowest, Q2, Q3, and Q4-the highest). For high-density lipoprotein (HDL) cholesterol, the levels were classified and analysed by sex-specific quartile. The ranges of total cholesterol 


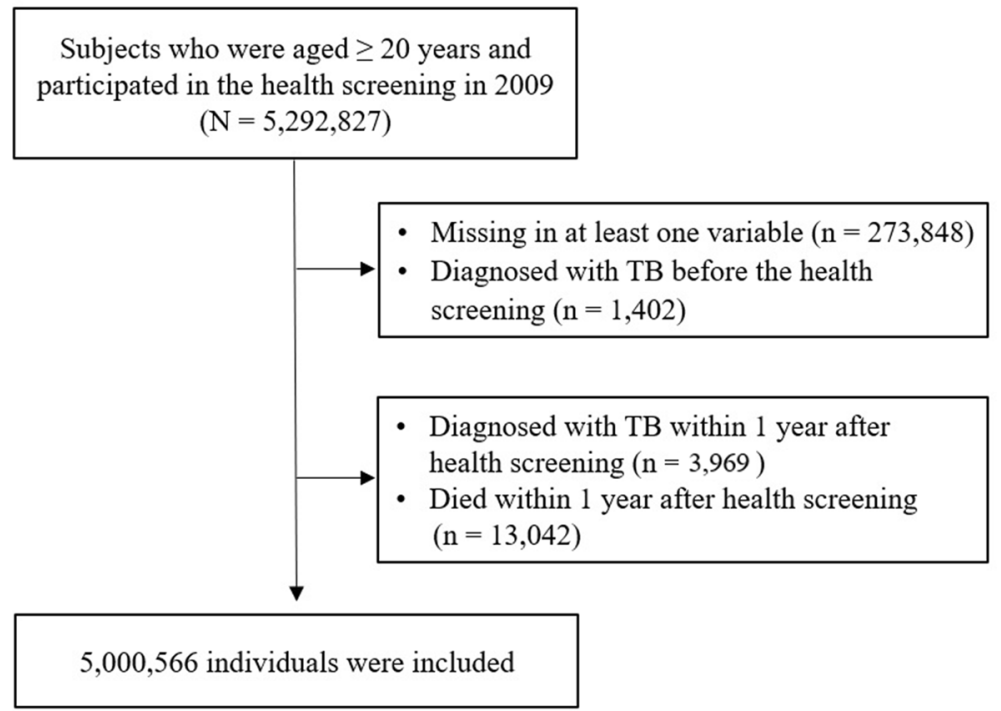

Figure 2. Flow chart.

level were $<170 \mathrm{mg} / \mathrm{dL}$ in Q1, 171-192 mg/dL in Q2, 193-217 mg/dL in Q3, and $\geq 218 \mathrm{mg} / \mathrm{dL}$ in Q4; for LDL cholesterol, the ranges were $<91 \mathrm{mg} / \mathrm{dL}$ in Q1, 92-111 mg/dL in Q2, 112-134 mg/dL in Q3, and $\geq 135$ in Q4; for triglycerides, the ranges were $<75 \mathrm{mg} / \mathrm{dL}$ in Q1, $75-108 \mathrm{mg} / \mathrm{dL}$ in Q2, $109-162 \mathrm{mg} / \mathrm{dL}$ in Q3, and $\geq 163 \mathrm{mg} / \mathrm{dL}$ in Q4; for HDL cholesterol in males, the ranges were $<44 \mathrm{mg} / \mathrm{dL}$ in Q1, 44-50 mg/dL in Q2, 51-59 mg/dL in Q3, and $\geq 60 \mathrm{mg} / \mathrm{dL}$ in Q4; for HDL cholesterol in females, the ranges were $<49 \mathrm{mg} / \mathrm{dL}$ in Q1, 49-56 $\mathrm{mg} / \mathrm{dL}$ in Q2, $57-66 \mathrm{mg} / \mathrm{dL}$ in $\mathrm{Q} 3$, and $\geq 67 \mathrm{mg} / \mathrm{dL}$ in $\mathrm{Q} 4$.

Covariates. Based on the results from the self-administered questionnaire, the subjects were classified according to their physical activity as none, irregular, and regular. Regular physical activity was defined as performing $>30$ min of moderate physical activity at least 5 times per week or $>20$ min of strenuous physical activity at least 3 times per week. Smoking status was classified into never, former, and current smokers. The subjects' rate of alcohol consumption was classified as none ( $0 \mathrm{~g} /$ day $)$, moderate $(<30 \mathrm{~g} /$ day $)$, and heavy ( $\geq 30 \mathrm{~g} /$ day $)$.

BMI was calculated as the subject's weight in kilograms divided by their height in meters squared, and the resulting BMI values were classified into 5 categories according to the Asia-Pacific criteria of the World Health Organization $^{32}$ : underweight $\left(<18.5 \mathrm{~kg} / \mathrm{m}^{2}\right)$, normal $\left(18.5-23 \mathrm{~kg} / \mathrm{m}^{2}\right)$, overweight $\left(23-25 \mathrm{~kg} / \mathrm{m}^{2}\right)$, and obeseto-severely obese $\left(\geq 25 \mathrm{~kg} / \mathrm{m}^{2}\right)$. We used the Modification of Diet in Renal Disease equation to calculate the glomerular filtration rate values ${ }^{33}$.

Regarding comorbidities, COPD was defined as ICD-10 codes J42-J44 except for J43.0 (unilateral emphysema), and asthma was defined as ICD-10 codes J45-J46. Comorbid COPD and asthma were assessed during the enrollment period ${ }^{34}$.

The determination of income level was based on monthly insurance premiums because insurance contributions are determined by income level and not health risk in Korea. Low income was defined as the lowest quartile of monthly insurance premiums.

Study outcome. The main study outcome was incident active TB during the follow-up period. Since 2005, the Korean NHIS has provided a special co-payment reduction program for all patients diagnosed with active TB to decrease the burden of TB on the nation. Specific insurance codes (V000, V206, and V246) are required for patients with active TB after confirmation of their diagnosis, and TB patients then receive free TB-related medical care. Because the NHIS database contains complete information about insured medical services throughout the country, the claims database enabled us to review all patients with active TB in the nation using their unique insurance $\operatorname{codes}^{35}$.

Statistical analysis. Continuous variables were compared using two-tailed Student's t-testing, and categorical variables were compared using $\chi^{2}$ testing. The incidence rate of the primary outcome was calculated by dividing the number of incident cases by the total follow-up duration (10,000 person-years). Univariable and multivariable Cox regression analyses were performed to evaluate the HRs of TB incidence according to the quartiles of lipid profiles. Multivariable models included the following: (1) age, sex, smoking status, alcohol consumption, physical activity, BMI, DM, asthma or COPD, glomerular filtration rate (model 1); (2) the variables in model 1 and statin use (model 2). To examine possible effect modification by subject characteristics, we conducted stratified analyses by age ( $<65$ vs. $\geq 65$ years), BMI, DM status, and statin use. All statistical analyses were performed using SAS version 9.4 (SAS Institute Inc., Cary, NC, USA), and a two-tailed $p$ value $<0.05$ was considered to indicate statistical significance. 
Ethics statement. This study was approved by the Institutional Review Board of Hanyang University Hospital (IRB No. 2020-11-019-001). The anonymity of the data is guaranteed, and no individually identifiable information is included; therefore, informed consent was waived in this study. The present study complied with the Declaration of Helsinki.

\section{Data availability}

The datasets generated and/or analysed during the current study are available from the corresponding author on reasonable request.

Received: 25 May 2021; Accepted: 27 July 2021

Published online: 10 August 2021

\section{References}

1. World Health Organization. Health at a Glance: Asia/Pacific 2020 (Date last accessed 11 December 2020): https://www.oecd-ilibr ary.org/content/publication/26b007cd-en.

2. Kim, J. H. \& Yim, J.-J. Achievements in and challenges of tuberculosis control in South Korea. Emerg. Infect. Dis. 21(11), 1913 (2015).

3. Oxlade, O. \& Murray, M. Tuberculosis and poverty: Why are the poor at greater risk in India?. PLoS ONE 7(11), e47533. https:// doi.org/10.1371/journal.pone.0047533 (2012).

4. Duarte, R. et al. Tuberculosis, social determinants and co-morbidities (including HIV). Pulmonology 24(2), 115-119. https://doi. org/10.1016/j.rppnen.2017.11.003 (2018).

5. Lönnroth, K. et al. A consistent log-linear relationship between tuberculosis incidence and body mass index. Int. J. Epidemiol. 39(1), 149-155. https://doi.org/10.1093/ije/dyp308 (2010).

6. Taylor, G. O. \& Bamgboye, A. E. Serum cholesterol and diseases in Nigerians. Am. J. Clin. Nutr. 32(12), 2540-2545. https://doi. org/10.1093/ajcn/32.12.2540 (1979).

7. Akpovi, D. C. et al. Tuberculosis treatment raises total cholesterol level and restores high density lipoprotein cholesterol (HDLC) in patients with pulmonary tuberculosis. Afr. J. Biotechnol. 12(41), 6019-6024 (2013).

8. Gebremicael, G. et al. Lipid profile in tuberculosis patients with and without human immunodeficiency virus infection. Int. J. Chronic Dis. 2017, 3843291-3843391. https://doi.org/10.1155/2017/3843291 (2017).

9. Martens, G. W. et al. Hypercholesterolemia impairs immunity to tuberculosis. Infect. Immun. 76(8), 3464. https://doi.org/10.1128/ IAI.00037-08 (2008).

10. Dooley, K. E. \& Chaisson, R. E. Tuberculosis and diabetes mellitus: Convergence of two epidemics. Lancet Infect. Dis. 9(12), 737-746. https://doi.org/10.1016/S1473-3099(09)70282-8 (2009).

11. Jeon, C. Y. \& Murray, M. B. Diabetes mellitus increases the risk of active tuberculosis: A systematic review of 13 observational studies. PLoS Med.5(7), e152. https://doi.org/10.1371/journal.pmed.0050152 (2008).

12. Litvinov, D. Y., Savushkin, E. V. \& Dergunov, A. D. Intracellular and plasma membrane events in cholesterol transport and homeostasis. J. Lipids 2018, 3965054-3965154. https://doi.org/10.1155/2018/3965054 (2018).

13. Rao, S. Serum cholesterol, HDL, LDL levels in pulmonary tuberculosis: A clinico-radiological correlation and implications. Infect. Dis. Clin. Pract. 17(2), 99-101 (2009).

14. Deniz, O. et al. Serum total cholesterol, HDL-C and LDL-C concentrations significantly correlate with the radiological extent of disease and the degree of smear positivity in patients with pulmonary tuberculosis. Clin. Biochem. 40(3-4), 162-166. https://doi. org/10.1016/j.clinbiochem.2006.10.015[publishedOnlineFirst:2007/01/16] (2007).

15. Soh, A. Z. et al. Dietary cholesterol increases the risk whereas PUFAs reduce the risk of active tuberculosis in Singapore Chinese. J. Nutr. 146(5), 1093-1100. https://doi.org/10.3945/jn.115.228049 (2016).

16. Albanna, A. S. et al. Serum lipids as biomarkers for therapeutic monitoring of latent tuberculosis infection. Eur. Respir. J. 42(2), 547. https://doi.org/10.1183/09031936.00064713 (2013).

17. Duan, H. et al. Statin use and risk of tuberculosis: A systemic review of observational studies. Int. J. Infect. Dis. 93, 168-174. https:// doi.org/10.1016/j.ijid.2020.01.036 (2020).

18. Liu, C. H., Liu, H. \& Ge, B. Innate immunity in tuberculosis: host defense vs pathogen evasion. Cell. Mol. Immunol. 14(12), 963-975. https://doi.org/10.1038/cmi.2017.88 (2017).

19. Bensinger, S. J. et al. LXR signaling couples sterol metabolism to proliferation in the acquired immune response. Cell 134(1), 97-111. https://doi.org/10.1016/j.cell.2008.04.052 (2008).

20. Zhu, X. et al. Increased cellular free cholesterol in macrophage-specific Abcal knock-out mice enhances pro-inflammatory response of macrophages. J. Biol. Chem. 283(34), 22930-22941. https://doi.org/10.1074/jbc.M801408200 (2008).

21. Gatfield, J. \& Pieters, J. Essential role for cholesterol in entry of mycobacteria into macrophages. Science 288(5471), 1647-1650. https://doi.org/10.1126/science.288.5471.1647 (2000).

22. Chyu, K.-Y. et al. Cholesterol lowering modulates T cell function in vivo and in vitro. PLoS ONE 9(3), e92095. https://doi.org/10. 1371/journal.pone.0092095 (2014).

23. Kim, S. J. et al. Association of body mass index with incident tuberculosis in Korea. PLoS ONE 13(4), e0195104. https://doi.org/ 10.1371/journal.pone.0195104 (2018).

24. Park, S. et al. Association of CKD with incident tuberculosis. Clin. J. Am. Soc. Nephrol. 14(7), 1002. https://doi.org/10.2215/CJN. 14471218 (2019).

25. Miner, M. D. et al. Role of cholesterol in Mycobacterium tuberculosis infection. Indian J. Exp. Biol. 47(6), 407-11 (2009).

26. Qiu, G. \& Hill, J. S. Atorvastatin inhibits ABCA1 expression and cholesterol efflux in THP-1 macrophages by an LXR-dependent pathway. J. Cardiovasc. Pharmacol. 51(4), 388-395 (2008).

27. Dutta, N. K. et al. Adjunctive host-directed therapy with statins improves tuberculosis-related outcomes in mice. J. Infect. Dis. 221(7), 1079-1087. https://doi.org/10.1093/infdis/jiz517 (2019).

28. Guerra-De-Blas, P. D. C. et al. Simvastatin enhances the immune response against Mycobacterium tuberculosis. Front. Microbiol. https://doi.org/10.3389/fmicb.2019.02097 (2019).

29. Pérez-Guzmán, C. et al. A cholesterol-rich diet accelerates bacteriologic sterilization in pulmonary tuberculosis. Chest 127(2), 643-651. https://doi.org/10.1378/chest.127.2.643[publishedOnlineFirst:2005/02/12] (2005).

30. Song, S. O. et al. Background and data configuration process of a nationwide population-based study using the korean national health insurance system. Diabetes Metab. J. 38(5), 395-403. https://doi.org/10.4093/dmj.2014.38.5.395 (2014).

31. NHIS. National Health Examination Statistical Yearbook 2014 (National Health Insurence Service, Seoul, 2014).

32. Pan, W. H. \& Yeh, W. T. How to define obesity? Evidence-based multiple action points for public awareness, screening, and treatment: an extension of Asian-Pacific recommendations. Asia Pac. J. Clin. Nutr. 17(3), 370-374 (2008).

33. Inker, L. A. et al. KDOQI US commentary on the $2012 \mathrm{KDIGO}$ clinical practice guideline for the evaluation and management of CKD. Am. J. Kidney Dis. 63(5), 713-735. https://doi.org/10.1053/j.ajkd.2014.01.416 (2014). 
34. Choi, H. et al. Population-based prevalence of bronchiectasis and associated comorbidities in South Korea. Eur. Respir. J. https:// doi.org/10.1183/13993003.00194-2019 (2019).

35. Cheol Seong, S. et al. Data resource profile: the national health information database of the National Health Insurance Service in South Korea. Int. J. Epidemiol. 46(3), 799-800. https://doi.org/10.1093/ije/dyw253 (2017).

\section{Author contributions}

Conceptualisation: Y.S.J., K.H., D.W.S., H.L. Data curation and formal analysis: K.H., D.K. Funding acquisition: H.L. Investigation and methodology: Y.S.K., K.H., D.K., D.W.S., H.L. Project administration: H.L. Resources and software: K.H., D.K. Supervision: Y.K., D.W.S., H.L. Visualization: Y.S.J. Writing—original draft: Y.S.J., K.H., D.W.S., H.L. Writing - review and editing: all author.

\section{Funding}

This work was supported by a National Research Foundation of Korea (NRF) grant funded by the Korea government (MSIT) (NRF-2020R1F1A1070468 and NRF-2021M3E5D1A01015176) and the Korea Medical Device Development Fund grant funded by the Korea government (the Ministry of Science and ICT, the Ministry of Trade, Industry and Energy, the Ministry of Health \& Welfare, the Ministry of Food and Drug Safety) (Project Number: 1711138447, KMDF_PR_20200901_0214). The funders had no role in study design, data analysis, and writing of the manuscript, and publication of the work.

\section{Competing interests}

The authors declare no competing interests.

\section{Additional information}

Supplementary Information The online version contains supplementary material available at https://doi.org/ 10.1038/s41598-021-95704-1.

Correspondence and requests for materials should be addressed to D.W.S. or H.L.

Reprints and permissions information is available at www.nature.com/reprints.

Publisher's note Springer Nature remains neutral with regard to jurisdictional claims in published maps and institutional affiliations.

(c) (i) Open Access This article is licensed under a Creative Commons Attribution 4.0 International License, which permits use, sharing, adaptation, distribution and reproduction in any medium or format, as long as you give appropriate credit to the original author(s) and the source, provide a link to the Creative Commons licence, and indicate if changes were made. The images or other third party material in this article are included in the article's Creative Commons licence, unless indicated otherwise in a credit line to the material. If material is not included in the article's Creative Commons licence and your intended use is not permitted by statutory regulation or exceeds the permitted use, you will need to obtain permission directly from the copyright holder. To view a copy of this licence, visit http://creativecommons.org/licenses/by/4.0/.

(C) The Author(s) 2021 